\title{
A Randomized Trial of eLearning for Hospital Trust Induction of Doctors
}

\author{
Muhammad Ali ${ }^{1, *}$, AJ Osborne ${ }^{1}$, Susan Nutland ${ }^{1} \&$ Joe Unsworth $^{1}$ \\ ${ }^{1}$ North Bristol NHS Trust, Dept. of Postgraduate Medical Education, Southmead Hospital \\ Bristol, Bristol, BS10 5NB, UK \\ *Corresponding author: North Bristol NHS Trust, Dept. of Postgraduate Medical Education, \\ Southmead Hospital Bristol, Southmead Road, Westbury-on-Trym, Bristol, BS10 5NB, UK. \\ E-mail: mohammadali75@hotmail.com
}

Received: November 4, 2014 Accepted: February 12, 2015 Published: March 28, 2015

doi:10.5296/ije.v7i1.6547ＵRL: http://dx.doi.org/10.5296/ije.v7i1.6547

\begin{abstract}
The induction of doctors to a new hospital is mandatory and includes the work-based assessment of mandatory knowledge. It has been delivered traditionally by lectures with recently increasing trend to deliver by electronic learning (eLearning). We compared eLearning and lectures for induction of hospital doctors by randomizing them into a Lecture Group (LG) and eLearning Group (eLG) using an opaque envelope technique. The LG attended lectures on their induction day while the eLG performed their induction using eLearning prior to joining the trust. The curriculum was the same for both groups. Primary and secondary outcomes were measured by the number of correct answers for all six modules' work-based assessment using multiple choice questions and by a questionnaire to assess the attitudes of the doctors who underwent eLearning towards their induction respectively.

All 133 doctors joining the NHS trust of 2 teaching hospitals over a five month period were included with no exclusion criteria. There were 63 individuals in the LG and 70 doctors in the eLG with no statistically significant differences in demographics. Improved learning outcomes were seen in the eLG in 5 of the 6 modules $(p<0.01)$. The eLearning was popular amongst the participants however they found it difficult to complete eLearning modules before joining the trust and perceived this as an extra burden. Our results indicate that an increase in the contribution of eLearning to the curriculum may improve learning outcomes in the medical workplace and can increase doctor availability on the first day in a new hospital.
\end{abstract}

Keywords: doctors, eLearning, traditional methods, hospital induction, learning outcomes 


\section{Introduction}

The impact of electronic learning (eLearning) as part of the curriculum in medical education is not yet well described. Twenty years ago, the World Wide Web was not available and computers were still a novelty. Now the "internet generation" is leaving medical school (Sanders J, Morrison C. 2007). This has helped drive an eLearning revolution where the learners may be more competent with the tool than their teachers. The traditional methods of teaching such as lectures have their own advantages but have been shown to be less flexible and can be perceived as outdated and inapplicable to the real-world demands of the workplace (Gardiner LF. 1997, Charles H 1998). eLearning, refers to the use of internet technologies and tools to deliver a broad array of solutions that enhance knowledge and performance (Rosenberg MJ. 2001). The tools can be used by trainers to improve the efficiency of their educational interventions and "may prove to complement the hospital environment (Glen AS. 2001)." Their use in medical schools is increasingly common especially in basic science courses (Ward JP, Gordon J, Field MJ, Lehman HP. 2001). The advantages of this approach include "being independent of time and place, reduced dissemination costs, increasing learning opportunities, and eliminating travel time and related expenses (Glen AS. 2001)." Despite this, eLearning has drawbacks, including "feelings of isolation, frustration with unfamiliar practices, a lack of necessary infrastructure and the new costs associated with on-line courses (Cook D. 2007)." eLearning studies have therefore shown a range of results in the past. Research into eLearning is still in infancy and many questions remain unanswered (Candy CP. 2007).

The induction of hospital doctors to a new hospital includes the work-based assessment of mandatory knowledge required for the doctor to start clinical work in their new workplace (GMC 2010). The main purpose is to ensure the effective integration of staff into the organization while ensuring patient safety. This requires evidence of having trained staff effectively in order to safeguard the welfare of the individual as well as maintaining the statutory and legal obligations of the hospital trust. Induction has therefore become a mandatory requirement in all NHS trusts and the requirement for doctors to undertake this is clearly set out by the General Medical Council in 'The new doctor (2009). The objectives of hospital trust induction programme are to demonstrate the minimum knowledge required of the doctor to practice safely in their new workplace.

In the past, induction has been delivered by a lecture programme for all new staff to attend on their first day of employment. Hospital induction by the lecture method is a time-consuming and costly process. There is also an administrative burden running the induction including monitoring the doctors successful attendance. New eLearning to replace lectures was therefore introduced over a period of 6 months with the aim of enhancing the teaching and learning process and reducing costs while simplifying administration. Our single hypothesis was that the introduction of eLearning to hospital induction would help doctors improve their knowledge related learning outcomes. We aimed to use a randomized trial to compare the introduction of eLearning with the traditional method of lectures to deliver the curriculum for the hospital induction. The two techniques would be correlated with the learning outcomes achieved. 


\section{Methods}

\subsection{Setting}

The study was carried in two teaching hospitals within one NHS trust in South-West England, that together recruit over 500 new junior doctors each year. Normally, 12 groups of the 6 induction modules have to be given each year. The recruitment for the trial was carried out from January to May, 2009

\subsection{Design}

Prospective data collection was performed. Flow through the study can be seen in the consort statement (2001) in Figure 1. The delivery of the hospital induction was either by eLearning or lectures. The six modules in the study were: warfarin prescription, consent, clinical risk management, vulnerable adults, equipment safety, and resuscitation. The same work-based assessments were used at the end of each module for both groups. This consisted of multiple choice questions to demonstrate the essential knowledge required to start work in the Trust. The doctors were randomly allocated to the two groups by placing their names into opaque envelopes which were then shuffled before being divided into two groups by an independent third party blinded to the contents.

The Lecture Group (LG) received the same on-going induction as originally delivered by lecture in the lecture theatre on the doctors' first day in the hospital. The eLearning group (eLG) received a training tracker online eLearning induction (Training tracker). The 6 modules were converted to eLearning modules (e-modules) using the power-point presentations which delivered the lectures to the LG. The first three modules (warfarin prescription, consent, clinical risk management) were available for all doctors but the final three (vulnerable adults, equipment safety, resuscitation) were developed during the study: thus not all doctors did all six modules on eLearning (Table 1). The modules are the copyright of the hospital trust but are available on request. Those doing eLearning answered on line while those at lectures answered on paper immediately after the lecture. The e-modules delivered exactly the same content but in an eLearning format allowing the eLG to perform the induction and work-based assessments in the 2 weeks period before joining the trust.

\subsection{Outcome measures}

\subsubsection{Main outcome measure:}

The number of correct answers for each module using multiple choice questions.

\subsubsection{Secondary outcome measure:}

A questionnaire was used to assess the attitudes of the doctors who underwent eLearning for their induction. This asked for agreement with statements relating to either the eLearning or the work-based assessment. Likert scales were used with participants responding to statements on a scale of 1-5 (strongly agreeing to strongly disagreeing) to various statements. A copy of the questionnaire is available on request. 


\subsection{Statistical analysis}

\subsubsection{Quantitative analysis:}

Statistical analysis was performed by Prism (Graphpad software 2012). Chi-square was used to compare the two populations and Mann-Whitney for analysis of the learning outcomes. Questionnaire responses: "strongly agree" and "agree" were grouped into "Agree" and "strongly disagree" and "disagree" were grouped into "Disagree."

\subsubsection{Qualitative analysis:}

All the documented thoughts recorded by the eLG in the comments section of the questionnaire were considered independently (and any disagreements resolved at a face to face meeting) in order to record any common themes identified.

Wiltshire research ethics committee advised that ethical approval was not required.

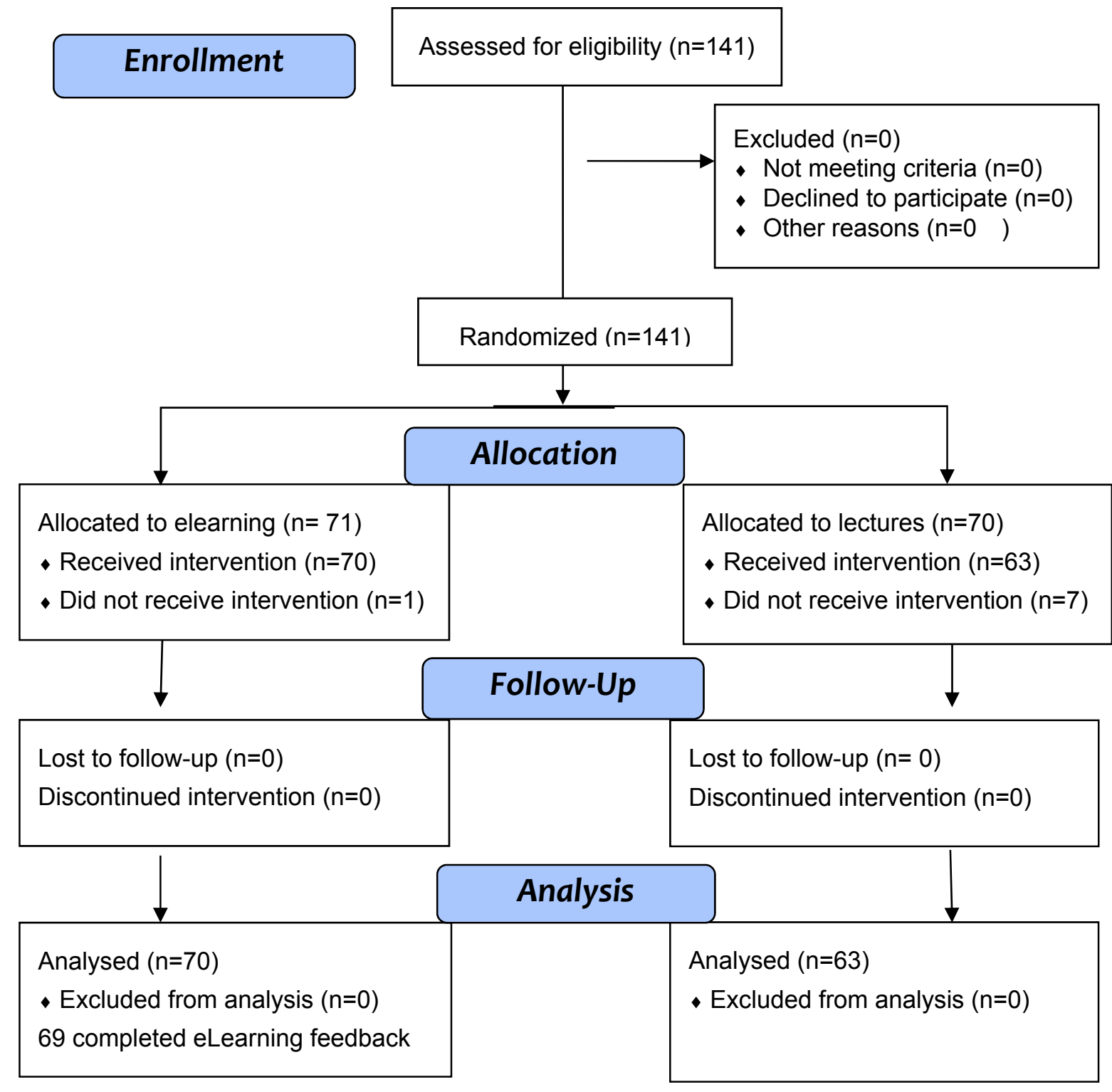

Figure 1. Consolidated Standards of Reporting Trials (CONSORT) 2010 Flow Diagram 
Retrieved on 10 august 2013 http://www.consort-statement.org/consort-statement/flow-diagram0/

Table 1. Demographics of Study Groups

\begin{tabular}{|c|c|c|c|c|c|}
\hline \multirow[t]{2}{*}{ Module } & \multicolumn{2}{|c|}{ eLearning } & \multicolumn{2}{|c|}{ Lecture Group } & \multirow[t]{2}{*}{ Significant } \\
\hline & Category & Grade & Category & Grade & \\
\hline \multirow[t]{2}{*}{ Warfarin } & Grade & $24 \mathrm{CT}, 46 \mathrm{ST}$ & Grade & $20 \mathrm{CT}, \quad 43 \mathrm{ST}$ & NS \\
\hline & Sex & $43 \mathrm{M}, 27 \mathrm{~F}$ & Sex & $38 \mathrm{M}, 25 \mathrm{~F}$ & NS \\
\hline \multirow[t]{2}{*}{ Consent } & Grade & $24 \mathrm{CT}, 46 \mathrm{ST}$ & Grade & $20 \mathrm{CT}, 43 \mathrm{ST}$ & NS \\
\hline & Sex & $43 \mathrm{M}, 27 \mathrm{~F}$ & Sex & $38 \mathrm{M}, \quad 25 \mathrm{~F}$ & NS \\
\hline \multirow[t]{2}{*}{ Risk } & Grade & $24 \mathrm{CT}, 46 \mathrm{ST}$ & Grade & $20 \mathrm{CT}, \quad 43 \mathrm{ST}$ & NS \\
\hline & Sex & $43 \mathrm{M}, 27 \mathrm{~F}$ & Sex & $38 \mathrm{M}, \quad 25 \mathrm{~F}$ & NS \\
\hline \multirow[t]{2}{*}{ Vulnerable adults } & Grade & $21 \mathrm{CT}, 39 \mathrm{ST}$ & Grade & $19 \mathrm{CT}, 38 \mathrm{ST}$ & NS \\
\hline & Sex & $35 \mathrm{M}, 25 \mathrm{~F}$ & Sex & $33 \mathrm{M}, 24 \mathrm{~F}$ & NS \\
\hline \multirow[t]{2}{*}{ Equipment } & Grade & $13 \mathrm{CT}, 20 \mathrm{ST}$ & Grade & $13 \mathrm{CT}, 17 \mathrm{ST}$ & NS \\
\hline & Sex & $17 \mathrm{M}, 16 \mathrm{~F}$ & Sex & $15 \mathrm{M}, 15 \mathrm{~F}$ & NS \\
\hline \multirow[t]{2}{*}{ Resuscitation } & Grade & $7 \mathrm{CT}, 5 \mathrm{ST}$ & Grade & $6 \mathrm{CT}, 7 \mathrm{ST}$ & NS \\
\hline & Sex & $7 \mathrm{M}, 5 \mathrm{M}$ & Sex & $6 \mathrm{M}, 7 \mathrm{~F}$ & NS \\
\hline
\end{tabular}

CT: Core Trainee

ST: Speciality Trainee

M: Male

F: Female

\section{Results}

Over a five month period a total of 133 doctors joined the trust: 1 doctor in eLearning and 7 doctors in standard group resigned before undertaking this. Prospective data collection was from January 2009 for five months during which time five groups required a hospital induction. There were 63 individuals in the LG and 70 doctors in the eLG for the first three modules with fewer in the last three modules. There were no statistically significant differences in demographics for each module including gender and grade of doctor (Table 1). Improved learning outcomes (better scores) were seen in the eLG in all 6 modules (statistically significant in 5 out of 6 modules $p<0.01$ ): (Table 2 ). 
Table 2. Results for Standard and eLearning Group

\begin{tabular}{|c|c|c|c|}
\hline Module & $\begin{array}{c}\text { eLearning Group } \\
\text { Scores }\end{array}$ & $\begin{array}{l}\text { Lecture Group } \\
\text { Scores }\end{array}$ & *p value \\
\hline \multirow[t]{2}{*}{ Warfarin } & $9(8-10)$ & $9(3-10)$ & NS \\
\hline & $(n=70)$ & $(n=63)$ & \\
\hline \multirow[t]{2}{*}{ Consent } & $5(4-5)$ & $4(1-4)$ & $\mathrm{P}<0.01$ \\
\hline & $(n=70)$ & $(n=63)$ & \\
\hline \multirow[t]{2}{*}{ Risk } & $10(8-10)$ & $8(2-10)$ & $\mathrm{P}<0.01$ \\
\hline & $(n=70)$ & $(n=63)$ & \\
\hline \multirow[t]{2}{*}{ Vulnerable adults } & $5(4-5)$ & $4(1-5)$ & $\mathrm{P}<0.01$ \\
\hline & $(n=60)$ & $(n=57)$ & \\
\hline \multirow[t]{2}{*}{ Equipment } & $4(4-5)$ & $4(1-5)$ & $\mathrm{P}<0.01$ \\
\hline & $(n=33)$ & $(n=30)$ & \\
\hline \multirow[t]{2}{*}{ Resuscitation } & $5(4-5)$ & $3(2-5)$ & $\mathrm{P}<0.01$ \\
\hline & $(\mathrm{n}=12)$ & $(\mathrm{n}=13)$ & \\
\hline
\end{tabular}

*Mann-Whitney

Table above shows the scores for the assessment of learning are presented as median and (range) for each module by learning group. $\mathrm{n}$ is the number of doctors undertaking each group.

69 of 70 doctors in eLG answered the feedback questionnaire. The quantitative analysis demonstrated a range of positive and negative attitudes as seen in Table 3 . The induction by eLearning was the method of choice (see Figure 2). There was also agreement that assessment should be part of the eLearning (see Figure 3).The eLearning was popular amongst the participants however they wanted protected paid time at work to complete the eLearning. The doctors found it difficult to complete eLearning modules before joining the trust and perceived this as an extra burden. Participant 33 commented "electronic induction should not be done in own time" while participant 51 wrote "electronic induction much better. 


\section{Macrothink}

Table 3. Results for eLearning Group Feedback Questionnaire

\begin{tabular}{clccc}
\hline No. & Questions & Agree & Undecided & Disagree \\
\hline 1. & Assessment should be part of induction & $41(59 \%)$ & $17(25 \%)$ & $11(16 \%)$ \\
2. & Assessment motivated me to learn & $27(39 \%)$ & $22(32 \%)$ & $20(29 \%)$ \\
3. & E-induction (electronic Induction) is an & $40(58 \%)$ & $11(16 \%)$ & $18(26 \%)$ \\
& extra burden & & & \\
4. & I can manage time for an e-induction & $17(39 \%)$ & $21(30 \%)$ & $21(30 \%)$ \\
5. & Change to e-induction is the future & $38(55 \%)$ & $15(22 \%)$ & $16(23 \%)$ \\
6. & E-induction saves time & $37(54 \%)$ & $18(26 \%)$ & $14(20 \%)$ \\
7. & E-induction is the method I would choose & $37(54 \%)$ & $12(17 \%)$ & $20(29 \%)$ \\
\hline
\end{tabular}

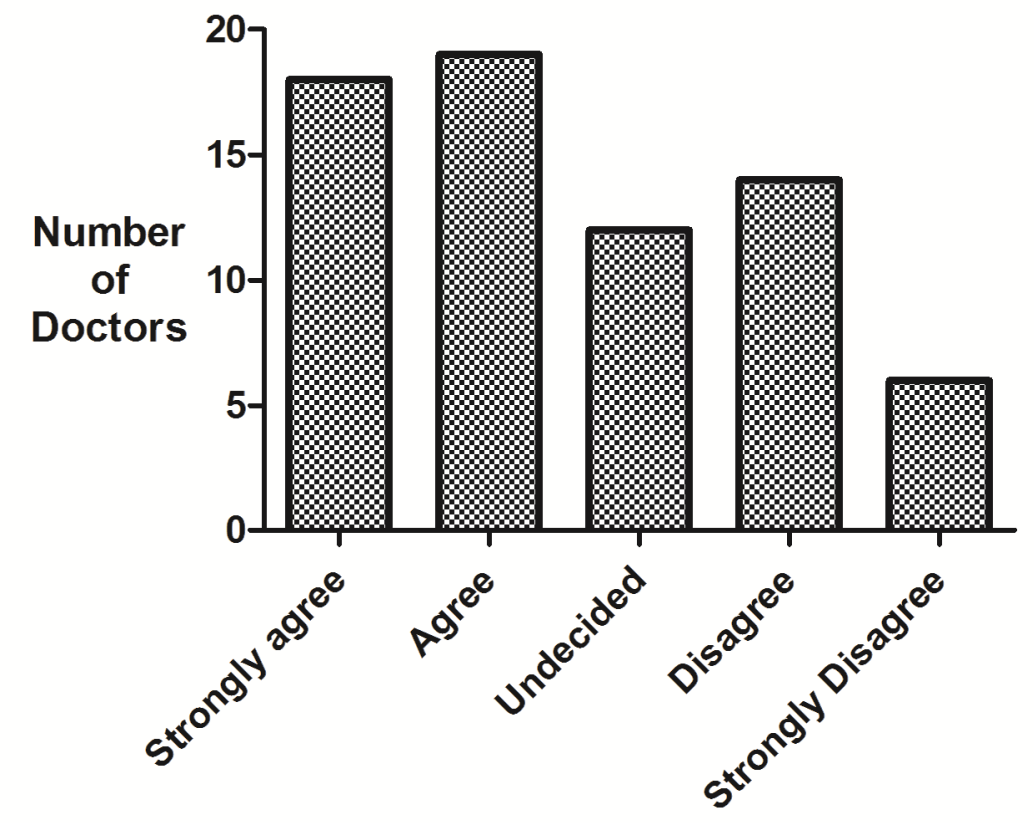

Doctors' Attitudes Towards eLearning in Hospital Induction

Figure 2. "I would choose eLearning". Based on the questionnaire results in response to the statement, "E learning is the method of hospital induction I would prefer if given a choice." 


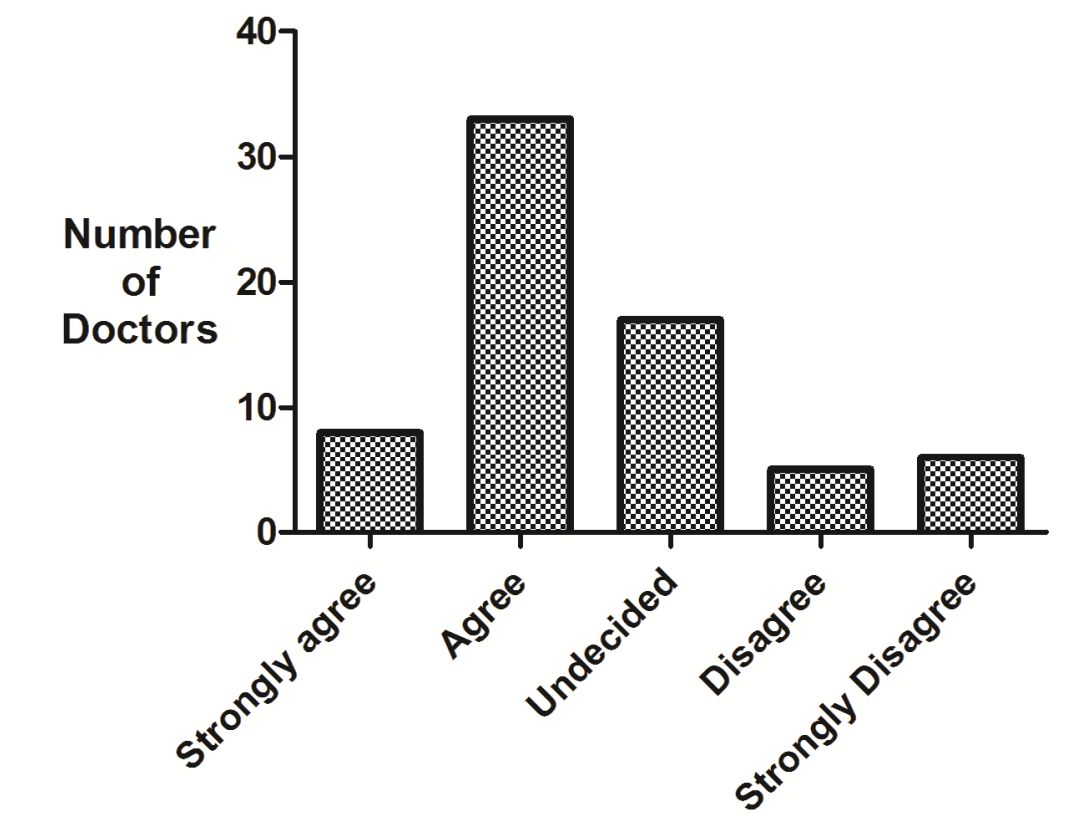

Doctors' Attitudes Towards Assessment in Hospital Induction

Figure 3. Work-based assessment of eLearning. Based on the questionnaire results in response to the statement, "Assessment should be part of my eLearning induction."

\section{Discussion}

Introducing eLearning to hospital induction presents a curriculum design hurdle before it can be introduced into the workplace. However, a review has shown eLearning has advantages over no intervention and is comparable to standard modes of teaching (Cook D. 2009). Our results show the eLG performed better than the LG in all six modules. Feedback is important when implementing change in teaching and the Doctors' attitudes towards the eLearning were divided with a range of answers seen. The induction by eLearning was well received (see Figure 3) and was felt to save time which can be utilized elsewhere. Indeed, releasing junior doctors from listening to lectures on their first day in a new hospital must be good for patient care - especially since this has been shown to be a dangerous day for patients (Jen MH, Bottle A, Majeed A, Bell D, Aylin P. 2009). However there was concern over finding time for the eLearning modules before joining the trust and the majority of the doctors thought eLearning placed an extra burden on them. There was agreement that assessment should be part of induction (see Figure 3) but only 39\% felt this assessment helped their learning. One explanation for this range of opinions may be the time management required to complete the online modules before joining the trust as reflected by one of the comments, "there needs to be protected time in the work-place for completing the e-modules." In addition eLearning is still new to the hospital workplace and both employers and employees are still unfamiliar with the method.

An evaluation of change in outcomes for learners' knowledge, skills or attitudes allows eLearning teachers to gauge programme effectiveness. The evaluation framework outlined by Kirkpatrick (1998) in the 1950s and later adapted to health care education (Barr H, Freeth D, 
Hammick M, Koppel I, Reeves S. 2000), can be used to evaluate eLearning interventions (Horton W. 2001). ${ }^{18}$ The Kirkpatrick model defines 4 levels of evaluation used in this situation: satisfaction, learning, change in learner behaviour and organizational change. Satisfaction is measured by the learner's reaction to the material which can be seen with our positive feedback from the questionnaire. Our results could also be graded as level two with evidence of learning in the Doctors' knowledge, attitudes and skills. Whether any change in clinical practice by the doctors or organisation occurs could now be a subject of future study.

Results similar to the improvements in learning outcomes seen here have been shown before with significant advantages of online teaching methods over traditional classroom methods found (Ochoa J. 2008, Jeffries P. 2001). eLearning has also been reported as producing enhanced performance (Dutton J. 2005), cognitive gains with higher satisfaction (Jeffries P. 2001), and improved test scores (Ochoa J. 2008). Cook (2009) identified 76 studies comparing an internet based instruction to a traditional teaching intervention such as lectures and found similar benefits in favour of elearning. Chumley Jones et al carried out another study of medical, nursing and dental literature (Chumley-Jones HS, Dobbie A, Alford CL. 2002). They found that in terms of knowledge, web based learning was at least equivalent to traditional methods. Learning delivery remains the most often cited advantage of eLearning and includes increased accessibility to information, ease in updating content, personalized instruction, ease of distribution, standardization of content and accountability (Rosenberg MJ 2001). The accessibility refers to the users' ability to find what is needed, when it is needed. This improved access to educational materials can be crucial as learning is often an unplanned experience (Ward JP, Gordon J, Field MJ, Lehman HP. 2001), although our teaching was both planned and mandatory.

Despite evidence of eLearning benefits, it is important to use it appropriately. Clark (1983), Friedman (1994) and Cook (2005b) argued that we need to clarify the use of eLearning by studying when to use it. eLearning may be a great way to teach neuro-anatomy, but only moderately effective for teaching examination of cranial nerves, and may be entirely ineffective for teaching a student how to tell a patient that he has cancer. The bottom line is that it is not possible to make a global statement comparing eLearning to face to face or any other instructional medium. Perhaps instead of asking 'if' we should use eLearning, we should ask 'when' to use this potentially powerful tool. Our study proves that eLearning is suitable for hospital trust induction with positive results in learning outcomes and ease of delivery to a large number of learners.

The attitudes towards eLearning seen here have also been described before with results demonstrating that students can have a positive opinion about eLearning (Chumley-Jones HS, Dobbie A, Alford CL. 2002; Cook DA. 2005b). These reports suggested this may be due to perceived ease of use and access, navigation, interactivity and user friendly interface design (Chumley-Jones HS, Dobbie A, Alford CL. 2002; Gibbons A, Fairweather P. 2000). However other studies reported equivalent or negative results. Carr found that student satisfaction was lower in web-based distant education despite higher rates of success. The author attributed this result to technical difficulties, including problems with internet connection and computer problems requiring technical support, which ultimately resulted in greater time expenditure by 
the students in the distance learning environment (Sarah C 2000). This may have been less relevant in our study 12 years later. In one of the other studies, students found eLearning less motivating than other formats (Hahne AK, Benndorf R, Frey P, Herzig S. 2005).

Reports in the non-medical literature on cost analysis have shown that eLearning can result in significant cost savings as much as $50 \%$ compared with traditional instructor lead learning. Savings are related to reduced instructor training time, travel costs, and labour costs, reduced institutional infrastructure and the possibility of expanding programmes with new educational technologies (Gibbons A, Fairweather P. 2000). However, eLearning is not inexpensive and may require large investments in faculty, time, money and space that needs to be justified to administrators and leadership. The savings can be made once the resources have been developed and the actual cost of providing the information to an expanding number of learners can be virtually free. Furthermore, although the cost of producing a single set of high quality eLearning resources may be high, it is considerably lower than the cost of producing similar and at times identical materials in many separate locations. Thus there can be significant savings to the service as whole by reducing duplication and redundancy (Candy CP 2007). In the times when NHS is facing many financial challenges, introduction of electronic induction may offer a way to save money without compromising the quality of services. Huge savings might be made if trusts shared their training packages.

The study does have some weaknesses and we accept that the use of multiple choice questions limits the assessment of competence. However the work-based assessments used assess the knowledge base which is mandatory to start work. In the trial itself there were four modules that the majority of the randomized participants followed and our conclusions are focused on those modules. For the remaining two modules the number of participants is smaller. For complete data we have presented all modules that are currently used, however we accept that from a scientific point of view, modules followed by twelve participants can only serve as a pilot. However, the preliminary analyses reported showed that the newly developed modules follow the same patterns as the other modules. The feedback collected by questionnaire from the eLG was limited and further research should focus more on qualitative results to expose any other important issues in order to further determine the effectiveness of this type of eLearning intervention.

We have used eLearning in the hospital induction of doctors and have shown this to be an effective method of learning. Since the completion of our study, the corporate trust induction at NBT has been completely switched to an electronic induction with departmental induction within the trust conducted by standard face to face methods. Prior to this study, corporate and departmental induction was eight hours long. However, after the introduction of eLearning, only departmental induction remained within the workplace, taking 3 hours, as the corporate induction was completed by doctors before joining the trust: compensation for the time taken may need to be considered. If the curriculum for the eLearning induction was agreed over the whole National Health Service then completion of training would not have to be repeated with every change in hospital workplace. There is now a Health Education England Programme for eLearning contributing to this revolution of medical and healthcare training called "e-Learning for Healthcare" with over sixty modules ranging from blood transfusion to safeguarding adults 
(Health Education England)

\section{Conclusions}

eLearning is an appropriate tool for use in hospital trust induction and effective part of the curriculum in the medical workplace with advantages seen over traditional methods of teaching. It has the capacity to save money and to release doctors for clinical duties, potentially saving lives. It deserves further study.

\section{Declaration of conflicting interests and sponsoring information}

All the authors report no conflicts of interest. There is no financial relationship of any of the authors with any sponsoring organization. There are no for-profit interests. In addition all authors included on the paper fulfil the criteria of authorship and there is no one else who fulfils the criteria but has not been included as an author.

\section{Funding acknowledgement}

This research received no specific grant from any funding agency in the public, commercial or not-for-profit sectors.

\section{References}

Barr, H., Freeth, D., Hammick, M., Koppel, I., \& Reeves, S. (2000). Evaluations of interprofessional education: a United Kingdom review of health and social care; Centre for the Advancement of Interprofessional Education, London, UK. Retrieved February 10, 2015 from http://www.caipe.org.uk/silo/files/evaluations-of-interprofessional-education.pdf

Candy, C. P. (2007). Elearning and NHS Connecting for Health: An Overview. Retrieved February 10, 2015 from http://eprints.usq.edu.au/19129/1/Candy_elearning_PV.pdf

Charles, H. (1998). A proper education. Change, 30, 12-19. http://dx.doi.org/10.1080/00091389809602637

Chumley-Jones, H. S., Dobbie, A., \& Alford, C. L. (2002). Web-based learning. Sound educational method or hype? A review of the evaluation literature. Academic Medicine, 77(10), S86-S93

Clarke, R. E. (1983). Reconsidering research on learning from media. Review of Educational Research, 53, 445-459

Cook, D. A. (2005b). The research we still are not doing. an agenda for the study of computer 
based learning. Academic Medicine, 80, 541-548

Cook, D. A. (2007). Web-based learning: pros, cons and controversies. Clinical Medicine, 7, 37-42. http://dx.doi.org/10.7861/clinmedicine.7-1-37

Cook, D. A. (2009). The failure of e-learning research to inform educational practice and what we can do about it. Medical Teacher, 31, 158-162 http://dx.doi.org/10.1080/01421590802691393

Dutton, J. (2005). Characteristics and Performance of Students in an on-line Section of Business Statistics. Journal of Statistics Education, 13(3). Retrieved February 10, 2015 from http://www.amstat.org/publications/jse/v13n3/dutton.html

Friedman, C. (1994). The research we should be doing. Academic Medicine, 69, 455-457

Gardiner, L. F. (1997). Producing dramatic increases in student learning; can we do it? National teaching and learning forum, 6(2), 8-10

Gibbons, A., \& Fairweather, P. (2000). Computer-based instruction. In: Tobias S, Fletcher J (eds). Training \& Retraining: A Handbook for Business, Industry, Government, and the Military. New York: Macmillan Reference USA, 410-42.

Glen, A. S. (2001). A comparison of distance learning and traditional learning environments. Retrieved August 10, 2013 from http://files.eric.ed.gov/fulltext/ED457778.pdf

GMC. (2009). The new doctor: guidance on foundation training: London. General Medical $\begin{array}{lllll}\text { Council. } & \text { Retrieved } & \text { February } & 10, & 2015\end{array}$ www.gmc-uk.org/New_Doctor09_FINAL.pdf_27493417.pdf_39279971.pdf

GMC. (2010). Workplace Based Assessment: A guide for implementation. London: General Medical Council. Retrieved February 10, 2015 from http://www.gmc-uk.org/Workplace_based_assessment_31381027.pdf

Graphpad software 2012. Graphpad prism version 5.00 for windows. San Diego California USA. Retrieved February 10, 2015 from http://www.graphpad.com

Hahne, A. K., Benndorf, R., Frey, P., \& Herzig, S. (2005). Attitude towards computer based learning determinants as revealed by a controlled interventional study. Medical Education, 39, 935-43. http://dx.doi.org/10.1111/j.1365-2929.2005.02249.x

Health Education England. "e-Learning for Healthcare". Retrieved February 10, 2015 from www.e-lfh.org.uk

Horton, W. (2001). Evaluating E-learning. Alexandria, VA: American Society for Training and Development, 1-125

Jeffries, P. (2001). Computer versus lecture: A comparison of two methods of teaching oral medication administration in a nursing skills laboratory. Journal of Nursing Education, 40(7), 323-29.

Jen, M. H., Bottle, A., Majeed, A., Bell, D., \& Aylin, P. (2009). Early In-Hospital Mortality 
following Trainee Doctors' First Day at Work. Public library of science, PLoS ONE, 4(9), 7103. http://dx.doi.org/10.1371/journal.pone.0007103

Kirkpatrick, D. (1998). Evaluating Training Programs.(2nd ed.). San Francisco: Berrett-Koehler, 1-265

Moher, D., Schulz, K. F., \& Altman, D. (2001). The CONSORT Statement. Revised Recommendations for Improving the Quality of Reports of Parallel-Group Randomized Trials. JAMA, 285(15), 1987-1991. http://dx.doi.org/10.1001/jama.285.15.1987

Ochoa, J. (2008). Randomized Comparison Between Traditional and Traditional Plus Interactive Web-Based Methods for Teaching Seizure Disorders. Teaching and Learning in Medicine, 20(2), 114-117.

Rosenberg, M. J. (2001). e-Learning: Strategies for delivering knowledge in the digital age. New York, McGraw-Hill, 3-311

Sanders, J., \& Morrison, C. (2007). What is the net generation? The challenge for future $\begin{array}{llll}\text { medical } & \text { education. } & \text { Medical } & \text { 29, }\end{array}$ http://dx.doi.org/10.1080/01421590601176380

Sarah, C. (2000). On-line psychology instruction is effective, but not satisfying, study finds. The Chronicle of Higher Education, 46(27), A48.

Training tracker web page. Retrieved February 10, 2015 from http://www.trainingtracker.co.uk/index.htm

Ward, J. P., Gordon, J., Field, M. J., \& Lehman, H. P. (2001). Communication and information technology in medical education. Lancet; 357, 792-96

\section{Copyright Disclaimer}

Copyright for this article is retained by the author(s), with first publication rights granted to the journal.

This is an open-access article distributed under the terms and conditions of the Creative Commons Attribution license (http://creativecommons.org/licenses/by/3.0/). 